\title{
Resistências ao golpe: o povo diz 2016 nunca mais
}

\section{Resistances to the Coup: the People Say 2016 Never Again}

\author{
Izabel Weber \\ Paula Bastone \\ Sérgio Barbosa
}

Resumo: A premissa deste trabalho é que se vive um contexto de crise da democracia representativa, onde a relação triangular Estado, sociedade e mercado é assimétrica e a democracia, mais formal do que substantiva. O Brasil, desde 2016, expressa esse contexto, quando, por meio de um processo controverso, porém dentro de uma legalidade formal, altera seu dirigente máximo e, com um novo representante ilegítimo, revela conflitos institucionais estruturantes, que estão por ruir essa relação triangular. No entanto, esses vértices não devem ser hostis entre si, mas o enfraquecimento de um e a sobreposição do outro são faces distintas de um mesmo desequilibrio sistémico que, se mitigado, permitiria oferecer gradação distinta de qualidade democrática. Neste sentido, não há um remédio específico que cure este desequilíbrio, mas «quebrar a patente» de um receituário tradicional neoliberal e austero e oferecer um coquetel de ferramentas participativas, pode ser a solução para uma sobrevida com qualidade desse tipo de governo, onde não só o poder está no demos, mas é o demos que possui o poder qualitativo de realizar algo. É preciso lembrar que a democracia representava, originalmente, a ampliação ou a substanciação do conceito de cidadania, motivada pela participação política da sociedade, que fez os reformadores clássicos ampliarem a composição do demos, bem como encontrar na deliberação o elemento qualificador dessa democracia. Em busca de uma maior participação deliberativa, os novíssimos movimentos sociais resistem e a partir dos aspectos comunicativos da ação coletiva constroem suas pautas e atuações. Este artigo levanta alguns desses exemplos diante do atual contexto institucional, económico e social do Brasil.

Palavras-chave: Ciberativismo, resistência política, participação política, movimentos sociais, Brasil.

\begin{abstract}
This article debates a crisis of representative democracy, where the triangular relationship -State, society and market- and the same time asymmetry and democracy, more formal than substantive. Brazil, since 2016, expresses this context when, through a controversial process, but within a formal legality, changes its maximum leader and, a new illegitimate representative, reveals structuring institutional conflicts that are falling apart this triangular relationship. Nonetheless, these vertices are not provided by being hostile to each other, but the weakening of one and an overlap of the other are distinct faces of a same systemic imbalance that, if mitigated, would allow to offer distinct gradation of democratic quality. In this sense, there is no specific remedy that cures this imbalance, but «breaking a patent» of a traditional neoliberal and austere prescription and offering different ways of participatory tools, can be a solution for quality-of-government survival, where only power is without demonstrations, but it is the demos that have the qualitative
\end{abstract}


power to accomplish something. We must remember that democracy originally represented the extension or a substantiation of the concept of citizenship, motivated by the political participation of society, which made the classical reformers broaden the composition of demos, as well as finding in the deliberation the qualifying element of democracy. In search of a greater participation of the market, the newest social movements resist from communicative of the collective action construct their guidelines and actions. This article brings theree cases in the current institutional, economic and social context of Brazil.

Palavras-chave: Cyberactivism, Political Resistance, Political Participation, Social Movements, Brazil.

\section{INTRODUÇÃO}

O Brasil sempre foi conhecido por ser um país de contrastes (Singer, 1986; Santos, 2008) -mas como uma democracia, minimamente conquistada e avaliada internacionalmente como gradualmente mais consistente, ao longo dos últimos quinze anos (Ames, 2003), demonstrou-se tão frágil e instável- (Gentili et al., 2016). Por que, após anos de políticas inclusivas e paulatina ampliação da participação nas diferentes fases das políticas públicas, objeto de estudo e atenção teórica de estudiosos de diversos países (Skidmore, 1994; Santos, 2009; Holston, 2008; Nylen e Dood, 2003), a sociedade civil apresentou-se tão desconetada, até pulverizada e ideologicamente inconsistente e, mesmo, contraditória -apesar da massiva, coesa e constante ocupação de espaços públicos desde 2013 (Singer, 2013)-. Como, apesar da melhora económica de determinado grupo social, alcançada ao longo dos últimos quinze anos, todas as sensações de descrédito e desconfiança descritas anteriormente motivaram uma mobilização social que propiciou uma alteração das lideranças políticas que, justamente, viriam para diminuir seus direitos e fragilizar sua relação de trabalho (propondo uma reforma trabalhista e previdenciária que diminuirá antigas conquistas sociais) em nome do crescimento económico do país? A grande preocupação que surge é o baixo grau de resiliência, observado do específico cenário brasileiro, da relação entre sociedade, Estado e mercado, tornando-a mais vulnerável (Porto, 2007). Partir da participação política e seus novos métodos e ferramentas de mobilização, contudo, pode contribuir na compreensão desse processo ainda em curso.

O objetivo geral deste artigo é analisar algumas formas de resistência realizadas pela população brasileira diante de onda de neogolpismo disfarçado de institucional que assombra a região neste século XXI (Ramos, Melo Filho, Loguercio, \& Ramos Filho, 2016). O estudo visa analisar formas de protesto e contestações não institucionais no Brasil e no exterior. Para tal, escolhemos três grupos distintos para analise:

O primeiro deles é o grupo do WhatsApp “\# Unidos contra o Golpe” (UCG). Nesta análise o objetivo é investigar como o uso das tecnologias da informação e comunicação (TIC's), em particular, o WhatsApp, vem se apresentando como 
elemento central para a convocação e a mobilização de ciberativistas nas democracias contemporâneas. Para tanto, será enfocado de que forma alguns usuários de um grupo do WhatsApp em Florianópolis organizaram protestos, no que se convencionou denominar usualmente de "ciberativismo". O método de investigação é constituído pela "netnografia" do grupo do WhatsApp, análise de quinze entrevistas semi-estruturadas e reflexões sobre as "postagens" do grupo analisado. Dessa forma, ressaltamos as motivações quanto ao uso político do WhatsApp, valendo-se de procedimentos metodológicos de cunho amplamente qualitativo. A partir desta experiência empírica, pretendemos averiguar se os múltiplos usos desta plataforma de tecnologia móvel representaram novas formas de participação política traduzidas ou não em mecanismos de ativação da cidadania e repolitização do social.

O segundo grupo analisado será os movimentos dos brasileiros residentes no exterior, tendo como célula de investigação principal o coletivo de brasileiros de esquerda em Coimbra-EBRAC. Suas ações, suas formas de interações internas e com outros grupos. A análise deste grupos assim como o de sua rede, e de outros coletivos que atuam desta forma, partirá de exame de suas "postagens" no Facebook, declarações e entrevistas.

O terceiro é o a Frente Povo Sem Medo -http://www.povosemmedo.orgque clama por novas eleições diretas (mesmo que não previstas na estrutura constitucional) como forma de legitimar a decisão do povo por uma orientação política, económica e social, e não apenas por um representante; um grupo que luta contra as políticas de austeridades propostas por um governo instável politicamente, sob uma orientação económica, política e social vencida nas urnas, com características semelhantes a outros movimentos sejam eles anti-sistémicos (Amin, 1987; Wallerstein, 1988), novos (Touraine, 2006; e Melucci, 1999) ou contra-hegemónicos (Arrighi, 2003). A pesquisa foi realizada com base na análise qualitativa dos discursos através da coleta, mineração e visualização das “postagens" e dados digitais de diversas redes sociais dos signatários da Frente.

\section{\#UNIDOSCONTRAOGOLPE}

O UCG foi criado a partir do desejo de lutar contra o golpe parlamentar (Souza, 2016) que se organizou no ano de 2016 no Brasil e reivindicou o retorno de Dilma Rouseff à Presidência da República. A indignação com a situação política do Brasil motivou os usuários/as inscritos/as no grupo do WhatsApp a refletirem e discutirem o cenário que o país atravessou nesse ano.

Esta parte do texto investiga o uso político deste grupo do Whats App com objetivo de analisar modalidades de participação política no âmbito da bibliografia sobre TIC's (Tecnologias da Informação e Comunicação). Em específico, buscamos entender o papel do WhatsApp na convocação e mobilização dos usuários inscritos no UCG (Barbosa, 2017).

Nosso objetivo é investigar o espaço de política criado neste grupo do Whats App sem estabelecer uma relação causal entre o UCG e participação política, mas desvendar o conteúdo social presente neste processo e captar esse novo estilo 
de participação criado pelos WhatsAppers, verificando o potencial mobilizador do aplicativo móvel para além das abordagens dicotômicas que, por um lado, defendem entusiasticamente o potencial democratizador da internet como uma espécie de "ágora digital" (Shirky, 2008), por outro, observam sua expansão como tendência à alienação e à desmobilização (Morozov, 2009).

Para isso, a estratégia metodológica adotada foi a "netnografia" do referido grupo em meados de Abril de 2016. A partir da netnografia, realizamos a análise das informações postadas pelos usuários do grupo no mês de setembro de 2016 e quinze entrevistas semi-estruturadas com residentes de Florianópolis inscritos no UCG (que serão apresentadas em outro momento).

A partir da pesquisa realizada, detectamos que os WhatsAppers são todos aqueles usuários inscritos em grupos da plataforma móvel que realizam seu uso intenso, com a possibilidade de utilizá-lo também para participação na vida política. Pelo aplicativo, o usuário/a é capaz de acumular funções políticas, pessoais, familiares, laborais, por meio da criação de grupos e envio de mensagens de texto, mensagens de voz, links, e imagens de forma instântanea. A denominação dos WhatsAppers é similar ao termo Avaazers -quaisquer indivíduos que decidem por assinar uma petição e aceitem receber informações das campanhas realizadas pela plataforma digital do Avar-.

Com a adesão enorme de usuários ao Whats App em todo o planeta, o Brasil seguiu o mesmo caminho: «a crescente penetração do aplicativo se fazia presente em 56\% dos aparelhos móveis brasileiros em 2014». (Savazoni e Copello, 2016, p. 118)

A expansão da tecnologia móvel aliada ao barateamento dos preços dos smartphones culminou em um maior acesso à rede virtual pela população brasileira (Hansen, 2016). Neste trabalho, consideramos que percepções de situações sociais experimentadas pelos WhatsAppers investigados podem passar por impressões e avaliações subjetivas acerca dos fenômenos políticos.

Em verdade, a formação das «paixões» na política, elemento-chave considerado por Chantal Mouffe (2016) na construção de formas coletivas foi diagnosticado no grupo investigado como uma avaliação subjetiva da motivação política. Por paixão, Chantal entende «um certo tipo de afeto comum que é mobilizado no campo político na constituição de formas de identificação» (Errejón e Mouffe, 2016, p. 53, tradução nossa) e «desempenham um papel fundamental na política, e a tarefa da política democrática não é superá-las por meio do consenso, mas elaborá-las de uma forma que estimule o confronto democrático» (Mouffe, 2015, p. 5).

O confronto entre identidades diversas no UCG permitiu florescer a «paixão» como elemento ímpar na constituição do espaço coletivo dentro do grupo. Foi o elemento que deu fôlego ao modus operandi do UCG, à medida que o choque de opiniões diversas entre os/as usuários/as foi crescendo concomitante ao entrosamento, que acabou por se transformar num ator coletivo.

De onde e como surge o UCG? O UCG foi criado no dia 30 de Março de 2016 às 19:19 (horário de Brasília) por um usuário de Florianópolis em um período próximo à votação pela Câmara dos Deputados do pedido de impeachment contra a presidenta Dilma Rouseff, com o propósito de reivindicar sua permanência na Presidência. 
No momento em que este texto era escrito, o UCG tinha cerca de 190 usuários, sendo aproximadamente mais de cem registrados no grupo com o DDD $(+48)$. O número de usuários/as varia de um dia para outro, ja que tanto podem entrar novos/as como sair antigos/as. No grupo, praticamente todos os números foram inscritos como administradores, o que permite adicionar novos integrantes e sinaliza uma organização de forma horizontal.

A maioria dos/as inscritos/as provém da região Sul do país, especialmente da cidade de Florianópolis, mas estando presentes WhatsAppers de outras regiões e alguns do exterior. Houve então uma transnacionalização do grupo sem qualquer pretensão inicial para isso. O UCG é formado por um grupo heterogéneo de atores sociais, tais como: educadores/as, engenheiros/as, petroleiros/as, geólogos/as, médicos/as, psicólogos/as, psicanalistas, arquitetos/as, sindicalistas, estudantes universitários/as, dentistas, atores/atrizes, poetas/poetisas, cronistas, bancários/as, músicos/as, professores/as universitários/as, mestres/as, doutores/as e políticos/as.

Os/As integrantes do grupo se posicionam maioritariamente como defensores/as de uma ideologia de esquerda: se orientam basicamente para a promoção da igualdade e para a mudança da ordem social. Bobbio (1994) explica que na esquerda percebemos o princípio do igualitarismo; o laicismo; a crítica das limitações ético-religiosas; a inexistência de conceitos absolutos de bem e mal; os interesses dos trabalhadores, que devem prevalecer sobre a necessidade de crescimento econômico; o antifascismo; e a identificação permanente com as classes inferiores da sociedade. A «conotação central da noção de esquerda apresentada por Norbeto Bobbio é com a ideia de igualdade. Segue sendo usada no mundo político e tem que ser mantida.» (Errejón e Mouffe, 2016, p. 131, tradução nossa)

Criamos um modus operandi para qualificar o modo de ação do UCG baseado na "netnografia" da pesquisa realizada. O grupo se uniu sob um projeto de esquerda formado por vários atores sociais. Os/As WhatsAppers criaram possibilidades de participar num coletivo e isso não envolveu uma solução necessariamente racional, e sim o florescimento das "paixões". Eles se uniram, mas reconheceram os direitos de outros/as usuários/as a exporem seus pontos de vista sobre o contexto político brasileiro. Houve o dissenso, mas com uma base de consenso, princípios éticos e morais que foi essencial para se organizarem em conjunto.

O modus operandi do UCG não decorreu necessariamente de uma estrutura programática, mas simplesmente daquilo que os/as usuários/as viveram de forma participativa e interativa no grupo. Para isso, utilizaram os dispositivos do Whats App para interagir politicamente, motivados/as pela indignação com a situação política brasileira e propelidos/as pelo entusiasmo de criar novas ações políticas que revelassem valores pró-democráticos.

O grupo teve sua evolução de forma contingencial e despertou demandas, frustrações e projetos de se unirem contra a onda da «direita que saiu do armario» (Messenberg, 2016) e o início do governo Temer no Brasil. Uma das questões 
fundamentais nesta pesquisa foi decifrar como esse modus operandi (Quadro 1) permitiu um espaço proveitoso para potenciais formas de participação política e aproximação de vínculos entre os/as usuários/as.

\section{Quadro 1: Fatores estruturantes e modus operandi dos Whatsappers no UCG}

\begin{tabular}{|c|c|c|c|}
\hline $\begin{array}{c}\text { Três } \\
\text { motivações- } \\
\text { chave para } \\
\text { criação do grupo }\end{array}$ & $\begin{array}{c}\text { Contexto } \\
\text { político brasileiro } \\
\text { que favoreceu a } \\
\text { união do UCG }\end{array}$ & $\begin{array}{l}\text { Criação do Grupo } \\
\text { no WhatsApp }\end{array}$ & $\begin{array}{l}\text { Resultado: } \\
\text { operandi UCG }\end{array}$ \\
\hline $\begin{array}{l}\text { - Parlamentares } \\
\text { conservadores } \\
\text { - Mídia } \\
\text { tradicional } \\
\text { parcial } \\
\text { - Judiciário } \\
\text { Espetacularizado }\end{array}$ & $\begin{array}{l}\text { - Impeachment } \\
\text { de Dilma } \\
\text { Rouseff; } \\
\text { - Início do } \\
\text { Governo Temer; } \\
\text {-Cortes drásticos } \\
\text { no orçamento } \\
\text { das políticas } \\
\text { sociais, redução } \\
\text { de benefícios, } \\
\text { destituição de } \\
\text { direitos, seja no } \\
\text { mundo do } \\
\text { trabalho, seja nas } \\
\text { políticas sociais e } \\
\text { nos serviços } \\
\text { públicos; } \\
\text { - Medidas anti- } \\
\text { sociais como a } \\
\text { aprovação da } \\
\text { PEC 241 ou } \\
\text { PEC 55; }\end{array}$ & $\begin{array}{l}\text { - Interações via } \\
\text { "postagens" a um } \\
\text { custo reduzido e } \\
\text { de forma } \\
\text { interativa; } \\
\text { - Convocação de } \\
\text { protestos, a partir } \\
\text { do cruzamento } \\
\text { online (Whats App / } \\
\text { off-line (ruas); } \\
\text { - Espaço coletivo } \\
\text { de articulação; } \\
\text { - Inserção da } \\
\text { política na prática } \\
\text { cotidiana; } \\
\text { - Paixão como } \\
\text { elemento } \\
\text { irracional que } \\
\text { permitiu maior } \\
\text { coesão ao grupo. }\end{array}$ & $\begin{array}{l}\text { - Processo } \\
\text { organizativo na forma } \\
\text { de redes: identificam } \\
\text { problemas; } \\
\text { compartilham } \\
\text { informações; } \\
\text { convocam protestos; } \\
\text { buscam soluções } \\
\text { conjuntas; e ainda } \\
\text { desenvolvem formas } \\
\text { de solidariedade para } \\
\text { garantir o respeito ao } \\
\text { direito de outros/as } \\
\text { usuários/as exporem } \\
\text { seus pontos de vista. } \\
\text { Sua organização } \\
\text { descentralizada é } \\
\text { basicamente formada } \\
\text { por diversos/as } \\
\text { protagonistas que não } \\
\text { reconhecem uma } \\
\text { liderança formal. }\end{array}$ \\
\hline
\end{tabular}

O modus operandi do UCG foi de fundamental importância para difundir informações não veiculadas pela mídia tradicional. Esta plataforma permitiu dar vOz a um público que não encontrou seu espaço em um período pós-impeachment no Brasil. Isso foi um fator preponderante para motivação de reunir diferentes WhatsAppers que compartilhavam um interesse político comum, por mais que existissem divergências explicitadas durante esta integração. Significa dizer: os usuários do UCG compreenderam «a democracia em um sentido ampliado, não como sinônimo de instituições, representação ou eleições, mas com uma criação sociopolítica e uma experiência subjetiva.» (Bringel e Pleyers, 2015, p. 12) 
Mais ainda: talvez a experiência do UCG mudou, de alguma maneira, a forma como os/as WhatsAppers "veem a política", no sentido de que o recrutamento para protestos, a disseminação instantânea das informações e organização das inúmeras atividades realizadas pelo grupo são feitas numa velocidade que satisfaz a democracia no século XXI.

\section{ESQUERDA BRASILEIRA EM COIMBRA - EBRAC}

O trabalho visa analisar as formas de atuação de coletivos no exterior contra o golpe de 2016. A pesquisa se concentra no coletivo de Coimbra, e a pesquisa foi feita através de entrevista e de coleta de informações no grupo do Whatsapp EBRAC.

O grupo Esquerda Brasileira em Coimbra teve sua fundação após a uma aula do professor Boaventura de Sousa Santos no dia 18 de março de 2016, por estudantes da Universidade de Coimbra, incluindo, posteriormente, investigadores/as brasileiros/as e estrangeiros/as à causa. Parte dos fundadores/as da EBRAC já não se encontra mais na cidade ou não tem mais condições de frequentar as reuniões e ações promovidas pelo grupo, devido a outros compromissos, revelando, assim, uma grande mobilidade dos participantes, já que parte dos/as brasileiros/as e outros membros estão apenas de passagem por Coimbra, em razão dos seus estudos. De acordo com a entrevistada, o grupo já existia anteriormente, mas foi com o processo do golpe que este grupo começou a se organizar politicamente em prol do Estado Democrático de direito, como se pode verificar no primeiro vídeo realizado pelos/as fundadores/as, ainda em março de 2016, no qual se posicionam e se apresentam. ${ }^{1}$

O grupo tende a se reunir para discutir a situação do Brasil e, no primeiro ano de existência, essas reuniões ocorriam quinzenalmente, sendo os lugares escolhidos no grupo de whatsapp. Contudo, durante as férias de verão na Europa, que vai de junho a setembro, as atividades ficam suspensas, sendo retomadas pelos/as participantes através de reuniões para debate interno, workshops ou seminários.

Além destes debates e reuniões, a EBRAC optou por fazer atividades em lugares públicos como forma de se posicionar em relação aos acontecimentos específicos no Brasil, como no caso referente à greve geral do dia 28 de abril de 2017. Em Portugal, no dia 25 de abril se comemora o dia da Revolução dos Cravos, ocorrendo marchas por várias cidades. Em Coimbra, foi coletado depoimentos de várias pessoas de diversas nacionalidades em apoio a greve geral no Brasil, que foi disponibilizado pela Mídia Ninja, gerando um retorno de apoio as atividades do grupo.

Outra forma de protesto organizado pela EBRAC é o protesto referente a vinda de pessoas ligadas ou que atuaram ao golpe, como o caso da jurista Flávia Piossovan que assumiu a secretaria dos Direitos Humanos do governos Temer.

\footnotetext{
${ }^{1}$ Video Estudantes da Universidade de Coimbra contra o Golpe e a favor da Democracia. Disponível em https://youtu.be/9wqBp06FI78, acessado dia 15 de outubro de 2017.
} 
Em razão da vinda dela a Portugal, o grupo se organizou, para se manifestarem durante a palestra dela, mas foram barrados. Foi proposto uma reunião com a jurista, após a palestra, mas os manifestantes, durante o evento, se reuniram e decidiram apenas ler uma carta de repúdio e não dialogar, por receio de que uma reunião pudesse ser interpretada como uma aceitação, mesmo que parcial, do atual governo.

A EBRAC tem como objetivo se posicionar em relação ao que está ocorrendo no Brasil e divulgar suas ações em Portugal. Suas principais formas de divulgação são o Facebook, e redes transnacionais com base no Brasil do quais seus membros fazem parte, e no exterior, como foi o caso da reunião de coletivos contra o golpe ocorrida em Amsterdã em janeiro de 2017, e as de se posicionarem através de atos pontuais, seminários e vídeos ou cartas produzidas por eles.

\section{A Frente Popular Povo Sem Medo}

O campo teórico dos movimentos sociais vem se consolidando e enriquecendo o já clássico debate em torno da ação coletiva, onde a composição; a capacidade de organização e mobilização; a resistência às instituições capitalistas; bem como os temas e os campos de atuação, são os critérios utilizados para diferenciar e categorizar esses grupos. Como o escopo deste trabalho não é analisar a teoria em si, mas enquadrar o estudo de caso escolhido, convém ressaltar as características do grupo ora estudado que permitem identifica-lo como um novíssimo movimento social anti-sistémico e contra-hegemónico, como uma força política com potencial poder de transformação social.

Desde que foi oficializado em outubro de 2015, foi possível perceber tanto a luta por direitos económicos (especialmente no tocante ao acesso à terra, à garantia de trabalho e à defesa de direitos e benefícios sociais); quanto políticos, diante dos diversos problemas que assolaram o país; bem como sociais (pela luta e defesa do reconhecimento de identidades étnicas e de minorias). Assim, mesmo tendo inicialmente por slogan "nossos sonhos não cabem nas urnas" o grupo enquadra-se na categoria de novos movimentos sociais, apesar de não constituir necessariamente uma oposição ao movimento operário e sindical dos quais, inclusive, aproximou-se ao longo dos últimos anos. Da mesma forma, ao contrário do presente nas teorias sobre os novos movimentos sociais, é possível encontrar nele um caráter de classe em seus discursos, a despeito de sua heterogénea composição.

Seguindo o pressuposto de que não é possível perceber um paradigma teórico latino-americano sobre os movimentos sociais dissociado das vertentes dos países do Norte, categorizar essa nova Frente recai sobre a análise de sua atuação. Esta é particular, pois a mesma absorve conceitos teóricos progressistas e clássicos do pensamento de esquerda, que dominou os novos movimentos sociais desde o fim da década de 60 (Gohn, 2004), aliada a novos pressupostos relacionados às mobilizações e às atuações em rede, de forma rápida e organizada. A resistência 
Astrolabio. Revista internacional de filosofía

institucional inicial, transformou-se em aproximação crítica com grupos de poder institucionalizados, consolidando aspirações políticas paulatinamente.

As novas ferramentas digitais foram, então, utilizadas tanto por grupos de manifestantes ou grupos de mobilização, bem como pelos movimentos sociais mais tradicionais. Ambos protagonizaram na região da América Latina como um todo, um novo ciclo de protesto desde o início do corrente século. Mas, o que os diferencia, além da efemeridade do primeiro tipo, apesar da composição fragmentada em termos sociais, bem como a amplitude das demandas vislumbradas em ambos, é que em movimentos sociais como a FPPSM, a consistência e algum tipo de identidade parece, justamente, apontar para uma tendência crescente de consolidação do movimento em torno de uma coerência teórica emancipatória, baseada em sua atuação social e política (Gohn \& Romão, 2011).

Ao acompanhar as ações dos movimentos sociais desde a crise económica que marcou o ano de 2008 e os subsequentes, mesmo no Brasil, percebe-se um aumento paulatino de mobilização, mesmo em movimentos tradicionais, formados entre 1930-40, bem como um resgate das Comunidades Eclesiásticas de base, marcadamente autuantes na década de 50 (Gohn, 2011).

Em recente evento em Brasília (Reunião do Pré-Alas, ocorrida em julho de 2017), Gohn, avaliando as modificações dos ciclos de manifestações no Brasil desde 2013 até maio/junho de 2017, busca identificar e se revisitar frente ao já abordado pela autora sobre os coletivos e movimentos estudados, dividindo esses últimos em clássicos, novos e novíssimos. Neste último grupo incluía o $\mathrm{MBL}$ (Movimento Brasil Liberal) e o Vem Para Rua, ambos de orientação «liberal», os quais ela prefere identificar como «organizações mobilizatórias ou movientalistas».

Essas organizações, não podem ser confundidas com outros movimentos, apesar de terem ocupado as ruas do país em um mesmo período e, muitas vezes, com pautas semelhantes, como foi o caso da Copa e o aumento das tarifas dos transportes públicos. Todavia, esses grupos seguiram caminhos distintos, mesmo que novos partidos tenham surgido com apelos contemporâneos e ligados a esses grupos (Novo, "Podemos"), pois esses não respondem ao mesmo público de indignados.

De fato, em janeiro de 2015, alguns movimentos sociais já haviam se organizado, de forma a pressionar o então governo de Dilma Rousseff por "reformas populares", percebendo as dificuldades em avançar com as demandas sociais e ampliação política requeridas por esses grupos. Foi, então, criada a Frente pelas Reformas Populares (FPRP), mas apenas 13, dos 26 grupos que a constituía, contribuíram para a composição da FPPSM. Os movimentos e as alas mais progressistas atores políticos, tanto dos movimentos quanto os institucionais, acabaram por reorientar seus projetos.

No entanto, o fator golpe, mesmo com as inúmeras críticas ao Partido dos Trabalhadores, acabou por influenciar alguns dos coletivos e dos movimentos, que nasceram como oposição, a unir esforços para evitar a consolidação de um período de extrema austeridade que já se apresentava e de limitação democrática. Como exemplo, os grupos "Coletivo Construção", "Juventude Marxista", disputavam 
espaço e criticavam a gestão da "União Nacional dos Estudantes", mas todos se uniram nas novas frentes formadas. Assim, utilizando as ferramentas "Social Searcher", "Keyhole", "Google trands" e "Google Social Search", é possível perceber tanto a consolidação da nova Frente, quanto a efemeridade de grupos mobilizatórios, que transitaram por essas frentes, conforme Quadro 2, abaixo.

\section{Quadro 2: Composição das Frentes FPRP e FPSM}

\begin{tabular}{|l|l|}
\hline \multicolumn{1}{|c|}{ Frente pelas Reformas Populares - } & \multicolumn{1}{|c|}{$\begin{array}{c}\text { Frente Nacional de Mobilização } \\
\text { Povo Sem Medo - PMPSM } \\
\mathbf{( 0 8 / 1 0 / 2 0 1 5 )}\end{array}$} \\
\hline $\begin{array}{l}\text { Ação Franciscana de Ecologia e } \\
\text { Solidariedade }\end{array}$ & $\begin{array}{l}\text { Associação Nacional dos Pós } \\
\text { Graduandos (ANPG) }\end{array}$ \\
\hline $\begin{array}{l}\text { Articulação Igrejas e Movimentos } \\
\text { Populares }\end{array}$ & Bloco de Resistência Socialista \\
\hline $\begin{array}{l}\text { Central de Movimentos Populares } \\
\text { (CMP) }\end{array}$ & Brigadas Populares \\
\hline Central Única dos Trabalhadores (CUT) & $\begin{array}{l}\text { Central dos Trabalhadores e } \\
\text { Trabalhadoras do Brasil (CTB) }\end{array}$ \\
\hline Coletivo Arrua & Central Única dos Trabalhadores (CUT) \\
\hline Coletivo Juntos & Círculo Palmarino \\
\hline Coletivo Rua & Coletivo Construção \\
\hline $\begin{array}{l}\text { Conselho Nacional de Igrejas Cristãs } \\
\text { (CONIC) }\end{array}$ & Coletivo Cordel \\
\hline Fora do Eixo & Coletivo de Literatura Marginal \\
\hline $\begin{array}{l}\text { Fórum Ecumênico ACT Aliança Brasil } \\
\text { (FEACT) }\end{array}$ & Coletivo de Mulheres Olga Benário \\
\hline $\begin{array}{l}\text { Igreja Povo de Deus em Movimento } \\
\text { Intersindical - Central da Classe } \\
\text { Trabalhadora }\end{array}$ & Coletivo Juntos \\
\hline $\begin{array}{l}\text { Juventude Socialismo e Liberdade } \\
\text { (JSOL) }\end{array}$ & $\begin{array}{l}\text { Federação Nacional dos Estudantes do } \\
\text { Ensino Técnico (Fenet) }\end{array}$ \\
\hline $\begin{array}{l}\text { Movimento dos Trabalhadores Rurais } \\
\text { Sem Terra (MST) } \\
\text { IPDM Povo de Deus em Movimento } \\
\text { Teto (MTST) }\end{array}$ & $\begin{array}{l}\text { Intersindical - Central da Classe } \\
\text { Trabalhadora * }\end{array}$ \\
\hline Movimento Nós da Sul & Juventude da Esquerda Marxista \\
\hline $\begin{array}{l}\text { Movimento Popular por Moradia } \\
\text { (MPM) }\end{array}$ & $\begin{array}{l}\text { Juventude Socialismo e Liberdade } \\
\text { (JSOL) }\end{array}$ \\
\hline Mídia Ninja (oriunda do Fora do Eixo)
\end{tabular}


Astrolabio. Revista internacional de filosofía Año 2018 Núm. 22. ISSN 1699-7549. pp. 151-166 doi: 10.1344/astrolabio2018.22.13

\begin{tabular}{|c|c|}
\hline $\begin{array}{l}\text { Frente pelas Reformas Populares - } \\
\text { FPRP }(22 / 01 / 2015)\end{array}$ & $\begin{array}{c}\text { Frente Nacional de Mobilização } \\
\text { Povo Sem Medo - PMPSM } \\
(08 / 10 / 2015)\end{array}$ \\
\hline $\begin{array}{l}\text { Ação Franciscana de Ecologia e } \\
\text { Solidariedade }\end{array}$ & $\begin{array}{l}\text { Associação Nacional dos Pós } \\
\text { Graduandos (ANPG) }\end{array}$ \\
\hline Partido Socialismo e Liberdade (PSOL) & $\begin{array}{l}\text { Movimento de Luta nos Bairros, Vilas e } \\
\text { Favelas (MLB) }\end{array}$ \\
\hline Rede Ecumênica da Juventude (REJU) & $\begin{array}{l}\text { Movimento dos Trabalhadores Sem } \\
\text { Teto (MTST) }\end{array}$ \\
\hline $\begin{array}{l}\text { Serviço Franciscano de Solidariedade } \\
\text { (Sefras) }\end{array}$ & Rede Emancipa de Educação Popular \\
\hline $\begin{array}{l}\text { Serviço Inter-Franciscano de Justiça, } \\
\text { Paz e Ecologia }\end{array}$ & Rua - Juventude Anticapitalista \\
\hline Uneafro & $\begin{array}{l}\text { Uneafro - União de Núcleos de } \\
\text { Educação Popular para Negras/os e } \\
\text { Classe Trabalhadora }\end{array}$ \\
\hline Unegro & $\begin{array}{l}\text { Unegro - União de Negros Pela } \\
\text { Igualdade }\end{array}$ \\
\hline União Brasileira de Mulheres (UBM) & União Brasileira de Mulheres (UBM) \\
\hline União da Juventude Socialista (UJS) & $\begin{array}{l}\text { União Brasileira dos Estudantes } \\
\text { Secundaristas (Ubes) }\end{array}$ \\
\hline \multirow[t]{3}{*}{ União Nacional dos Estudantes (UNE) } & União da Juventude Rebelião (UJR) \\
\hline & União da Juventude Socialista (UJS) \\
\hline & União Nacional dos Estudantes (UNE) \\
\hline
\end{tabular}

Fonte: Quadro elaborado pelos/as autores/as

Quando, então, a Frente foi lançada, em outubro de 2015, além do grande apoio da Frente Brasil Popular, ligada ao PT, outras 91 personalidades entre artistas (4), intelectuais e professores (67), servidores públicos (1), bem como profissionais liberais (10) de relevo no cenário nacional e políticos (9), independentemente de suas siglas, e 29 organizações tornaram-se signatárias da Carta de Lançamento. Dessas, de acordo com a definição nos respectivos documentos de formação temos: Associações Civis (5); Movimento Religioso (1); Coletivos (6); Imprensa Livre (1); Movimentos Sociais (12) e (3) Forças Sindicais. Sendo que 90\% desses grupos apresentam uma abrangência de atuação nacional, conforme observável pela Tabela 1 , abaixo.

Tabela 1: Signatários da Frente Povo Sem Medo quanto à abrangência

\begin{tabular}{|l|l|l|}
\hline SIGNATÁRIO & CONSTITUIÇÃO & ABRANGÊNCIA \\
\hline
\end{tabular}




\begin{tabular}{|c|c|c|}
\hline SIGNATÁRIO & CONSTITUIÇÃO & ABRANGÊENCIA \\
\hline $\begin{array}{l}\text { Movimento dos Trabalhadores Sem } \\
\text { Teto (MTST) }\end{array}$ & Movimento Social & nacional \\
\hline $\begin{array}{l}\text { Central Única dos Trabalhadores } \\
\text { (CUT) }\end{array}$ & Sindicato & nacional \\
\hline $\begin{array}{l}\text { Central dos Trabalhadores e } \\
\text { Trabalhadoras do Brasil (CTB) }\end{array}$ & Sindicato & nacional \\
\hline $\begin{array}{l}\text { Intersindical - Central da Classe } \\
\text { Trabalhadora * }\end{array}$ & Sindicato & nacional \\
\hline $\begin{array}{l}\text { União Nacional dos Estudantes } \\
\text { (UNE) }\end{array}$ & Associação Civil & nacional \\
\hline $\begin{array}{l}\text { União Brasileira dos Estudantes } \\
\text { Secundaristas (Ubes) }\end{array}$ & Associação Civil & nacional \\
\hline $\begin{array}{l}\text { Associação Nacional dos Pós } \\
\text { Graduandos (ANPG) }\end{array}$ & Associação Civil & nacional \\
\hline $\begin{array}{l}\text { Federação Nacional dos Estudantes } \\
\text { do Ensino Técnico (Fenet) }\end{array}$ & Associação Civil & nacional \\
\hline $\begin{array}{l}\text { Uneafro - União de Núcleos de } \\
\text { Educação Popular para Negras/os } \\
\text { e Classe Trabalhadora }\end{array}$ & Movimento Social & nacional \\
\hline Círculo Palmarino & Movimento Social & regional \\
\hline $\begin{array}{l}\text { Unegro - União de Negros Pela } \\
\text { Igualdade }\end{array}$ & Associação Civil & nacional \\
\hline $\begin{array}{l}\text { Igreja Povo de Deus em } \\
\text { Movimento (IPDM) }\end{array}$ & $\begin{array}{l}\text { Associação/Movimento } \\
\text { Religioso }\end{array}$ & regional \\
\hline União da Juventude Socialista (UJS) & Movimento Social & nacional \\
\hline Rua - Juventude Anticapitalista & Coletivo & nacional \\
\hline Coletivo Juntos & Coletivo & nacional \\
\hline União da Juventude Rebelião (UJR) & Movimento Social & nacional \\
\hline $\begin{array}{l}\text { Juventude Socialismo e Liberdade } \\
\text { (JSOL) }\end{array}$ & Movimento Social & nacional \\
\hline Coletivo Construção & Coletivo & nacional \\
\hline $\begin{array}{l}\text { Movimento de Luta nos Bairros, } \\
\text { Vilas e Favelas (MLB) }\end{array}$ & Movimento Social & nacional \\
\hline $\begin{array}{l}\text { Mídia Ninja (Narrativas } \\
\text { Independentes, Jornalismo e Ação) }\end{array}$ & Imprensa Livre & nacional \\
\hline $\begin{array}{l}\text { Coletivo Cordel - Coletivo } \\
\text { Revolucionário de Libertação }\end{array}$ & Coletivo & regional \\
\hline $\begin{array}{l}\text { União Brasileira de Mulheres } \\
\text { (UBM) }\end{array}$ & Movimento Social & nacional \\
\hline
\end{tabular}


Astrolabio. Revista internacional de filosofía Año 2018 Núm. 22. ISSN 1699-7549. pp. 151-166 doi: 10.1344/astrolabio2018.22.13

\begin{tabular}{|l|l|l|}
\hline \multicolumn{1}{|c|}{ SIGNATÁRIO } & \multicolumn{1}{|c|}{ CONSTITUIÇÃO } & ABRANGÊNCIA \\
\hline Bloco de Resistência Socialista & Movimento Social & nacional \\
\hline $\begin{array}{l}\text { Rede Emancipa de Educação } \\
\text { Popular }\end{array}$ & Movimento Social & nacional \\
\hline Coletivo de Mulheres Olga Benário & Coletivo & nacional \\
\hline Juventude da Esquerda Marxista & Movimento Social & nacional \\
\hline Coletivo de Literatura Marginal & Coletivo & nacional \\
\hline Brigadas Populares & Movimento Social & nacional \\
\hline
\end{tabular}

Fonte: Quadro elaborado pelos/as autores/as

Concentrando esforços apenas nos movimentos signatários, acrescida da Frente Brasil Popular (que contou com a adesão de 66 organizações) -uma vez que esta possui uma clivagem mais abrangente e não restrita aos grandes centros urbanos (contanto, inclusive, com 16 organizações voltas para as áreas rurais e pequenos agricultores), e de contar com organizações (11) que pertencem a ambas e, também pelo fato de terem promovido todos os atos em conjunto ou em mútuo apoio, inclusive ocupações- para realizar a análise dos grupos quanto à consistência e capacidade de mobilização. $\mathrm{O}$ intuito foi o de apontar o potencial dessas novas forças políticas não só de resistência, como de defesa de direitos e grande potencial para futura mobilização política, conforme ocorreu em outros países (Espanha e Itália, por exemplo).

Esse potencial começou a se transformar em realidade em junho do corrente ano, quando 103 grupos uniram suas forças em um único movimento a "Frente Ampla Nacional pelas Diretas Já". Esta nova Frente conta com 62 novos ("novo") grupos e movimentos, outros 6 que foram signatários das outras três Frentes, conforme o Gráfico 1, abaixo:

\section{Gráfico 1 - Percentual de Grupos em RelaÇÃo Às Frentes ENGaja-}

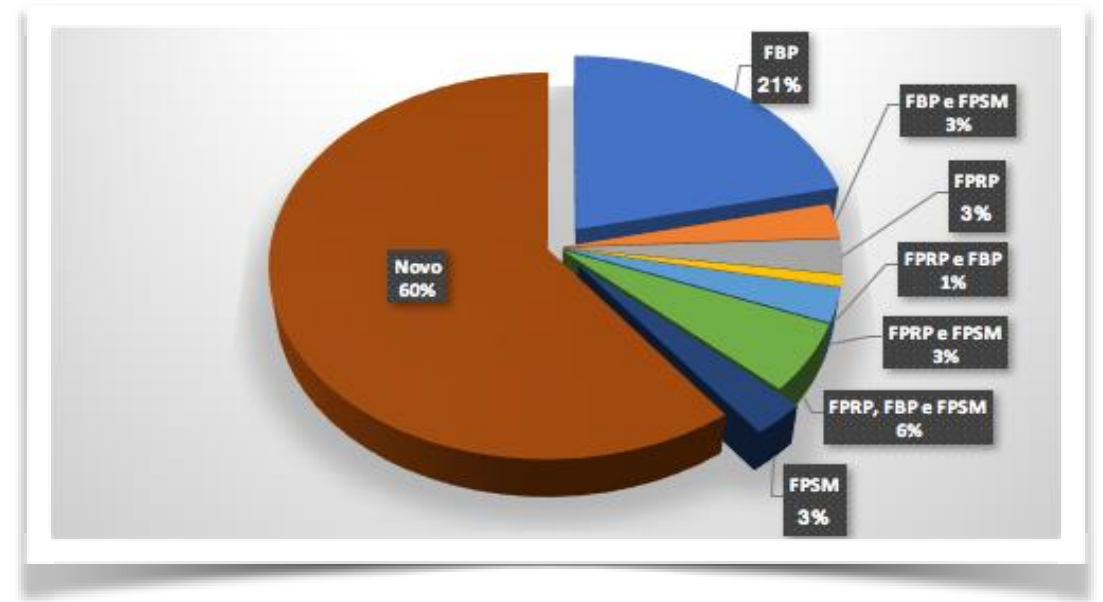

Fonte: Gráfico elaborado pelos/as autores/as. 
A simples apresentação desses dados, contudo, contraria a observação quanto à capacidade de atrair e manter coesas novas forças sociais de resistência, anti-sistémicas ou contra-hegemónicas, entorno de um objetivo comum tipicamente político -a realização de novas eleições diretas para Presidente da República-.

\section{CONCLUSÃo}

A democracia brasileira em tempos de mutações reconfigura-se a todo momento, e talvez por se tratar de um processo recente (1988) e em andamento, não podemos avaliar com precisão os reais impactos na vida dos indivíduos. No entanto, isso não nos impossibilita de buscar incessantemente novas chaves interpretativas para compreendê-la, na medida em que nela vicejamos modificações estruturais que incidem sobre nossos comportamentos, valores, hábitos, sobre nossa própria existência, e não simplesmente fornecer interpretações sobre o meio social que nos cerca sem conectar a teoria com a prática.

Tudo isso ainda é somado às incapazes intenções dos últimos governos de alavancar um reformismo realmente forte capaz de superar a alarmante desigualdade social que assola o Brasil. Nosso problema principal está longe de ser a corrupção, como foi fortemente propagado pela mídia brasileira em 2016, e sim ter mente que superar a desigualdade social e a concentração de renda é nos livrar de amarras que impede nosso progresso como nação.

Nosso maior desafio hoje perpassa também todas as democracias liberais contemporâneas, qual seja: entender que formar cidadãos não é a mesma coisa que formar consumidores. Se o culturalismo conservador e o economicismo superficial, conforme pontua Souza (2015), insistem na máxima de que a corrupção só existe no estado e o mercado, na verdade, é o reino de virtude por excelência, e ainda firmam este «mantra» como pilares recorrentemente utilizadas pela «ciencia» brasileira, nossa impressão é que continuaremos a «patinar no vazio sem atrito».

Só mesmo uma mudança em direção a uma teoria verdadeiramente crítica capaz de superar esta "gramática» brasileira que foi «colonizada até o osso» para captar nossa sociedade. Nestes cenários, deixaríamos nossa «tolice» para termos a «capacidade de julgar com autonomia e independencia» (Souza, 2015: 13) os fatos cotidianos experimentados e vivenciados pelos cidadãos brasileiros.

O que pode vir a substituir o "Governo Temer" no comando político do Brasil é incerto, mas este artigo versou sobre três exemplos de resistências que foram ignorados pela mídia tradicional brasileira. Para entender nosso momento político atual ao esboçar resistências que lutaram contra o impeachment da presidenta Dilma Rouseff em 2016, é nossa função reconhecer que as reflexões iniciais aqui desenvolvidas precisam de maior aprofundamento, tratando-se, portanto, de um campo aberto que está longe de ser encerrado.

O Brasil vive um momento peculiar: ou estas forças de resistência retomam os direitos sociais anteriormente conquistados ou assistiremos a uma definitiva implantação de forças conservadoras. Caminhamos para uma sociedade baseada na 
Astrolabio. Revista internacional de filosofía Año 2018 Núm. 22. ISSN 1699-7549. pp. 151-166 doi: 10.1344/astrolabio2018.22.13

superexploração dos trabalhadores, onde estamos assistindo a repressão das universidades, dos intelectuais, dos trabalhadores, das mulheres, da juventude, dos pobres e dos negros.

Olhar para a história do Brasil é reviver inúmeras rebeliões, revoltas e manifestações que foram duradouras, mas que contribuíram para tirar nossa imagem de país de espírito pacífico que não luta por conquistas e direitos. As três iniciativas destacadas neste texto retratam que ainda existe esperança e luta para construir valores democráticos para todo o povo brasileiro. Nossa aposta é justamente numa alternativa que contemple a construção de valores republicanos e cidadãos, ou seja, que contemple instrumentos para ajudar o Brasil voltar à normalidade democrática e construir reais valores de cidadania. O povo diz: 2016 nunca mais!

\section{REFERÊNCIAS BIBLIOGRÁFICAS}

Ames, B. (2003). Os entraves da democracia no Brasil. Rio de Janeiro: FGV Editora.

Barbosa, S. (2017). "WhatsApp e política: novas formas de ciberativismo em Florianópolis". Dissertação de mestrado, Programa de Pós-Graduação em Sociologia Política. Florianópolis: UFSC.

Bobbio, N. (1994). Destra e sinistra: Ragioni e significati di una distinzione politica (1 st). Roma: Donzelli.

Gentili, P., et al (2016). Golpe en Brasil. Ciudad Autónoma de Buenos Aires: Clacso; Fundación Octubre; Universidad Metropolitana para la Educación y el Trabajo (UMET). Acessado em http://www.cronicon.net/ paginas/edicanter/Ediciones115/Nota_18.

Bringel, B.,Pleyers, G. (2015). Junho de 2013... dois anos depois: polarização, imapactos e reconfiguração do ativismo no Brasil. Nueva Sociedad, pp. 4-17.

Errejón, Í., Mouffe, C. (2016). Construir pueblo: Hegemonía y radicalización de la democracia. Barcelona: Icaria.

Gohn, M. da G. (2004). Teoria dos Movimentos Sociais. Paradigmas Clássicos e Comtemporâneos (4th ed.). São Paulo, Brasil: Edições Loyola.

Gohn, M. da G. (2011). Movimentos Sociais no início do século XXI: Antigos e novos atores sociais. Editora Vozes.

Gohn, M. da G., \& Romão, J. E. (2011). Teorias dos Movimentos Sociais: O Debate Contemporâneo. Anais Do XV Congresso Brasileiro de Sociologia, 1-19. https://doi.org/2236-6636

Gutiérrez-Rubí, A. (2015). La política en tiempos de WhatsApp. Espanha: El país libros.

Holston, J. (2008). "Insurgent citizenship: Disjunctions of democracy and modernity in Brazil". Princeton: Princeton University Press.

Mouffe, C. (2015). Sobre o politico. São Paulo: Martins Fontes.

Mouffe, C. (2016). La paradoja democrática. Madrid: Gedisa editorial.

Morozov, E. (2009, May 19). The brave new world of slacktivism. Foreign Policy, pp. 17-19. Acessado em https://foreignpolicy.com/2009/05/19/the-bravenew-world-of-slacktivism/ 
Nylen, W., Dodd, L. (2003). Participatory democracy versus elitist democracy: lessons from Brazil. Santos, B. O Direito dos Oprimidos. São Paulo: Editora Cortez, 2014 e outros textos como o Democratizar a democracia, (2003).

Porto, M. F. S. (2007). "Uma ecologia política dos riscos: princípios para integrarmos o local e o global na promoção da saúde e da justiça ambiental". 2. ed. (revista e atualizada). Rio de Janeiro: Editora Fiocruz.

Ramos, G. T., Melo Filho, H. C., Loguercio, J. E., \& Ramos Filho, W. (2016). A classe trabalhadora e a resistência ao Golpe de 2016 (1st ed.). São Paulo, Brasil: Canal 6 Editora.

Santos, B. D. S. (2009). Democratizar a democracia: os caminhos da democracia participativa. In Reinventar a emancipação social: para novos manifestos (Vol. 1). Rio de Janeiro: Civilização Brasileira.

Santos, M. (2008). "O espaço dividido: os dois circuitos da economia urbana dos países subdesenvolvidos". In Milton Santos (Vol. 4). São Paulo: Editora da Universidade de São Paulo.

Savazoni, R., Copello, K. (2016). Brasil In: Sorj, B., Fausto, S. Ativismo politico em tempos de internet. São Paulo: Edições Plataforma Democrática.

Singer, A. (2013). "Brasil, junho de 2013, classes e ideologias cruzadas". Novos estudos-CEBRAP, (97), pp. 23-40.

Singer, P. I. (1986). Repartição da renda: pobres e ricos sob o regime militar. Rio de Janeiro: J. Zahar.

Shirky, C. (2009). Here comes everybody: The power of organizing without organizations, London: Penguin Press.

Skidmore, T. E. (1994). O Brasil visto de fora. São Paulo: Paz e Terra.

Souza, J. (2016). A radiografia do Golpe-Entenda como e por que você foi enganado. Leya.

Souza, J. (2015). A tolice da inteligência brasileira. São Paulo: Leya.

Streck, L. L. (2013). Democracia, jurisdição constitucional e presidencialismo de coalizão. Rio de Janeiro: Observatório da Jurisdição Constitucional.

Wallerstein, I. (2004). "Os movimentos: que significa hoje ser um movimento antisistêmico?" in: Wallerstein, I. (2003). O declínio do poder americano: os Estados Unidos em um mundo caótico. Rio de Janeiro: Contraponto. 